\title{
Symptommønstre ved kroniske søvnsykdommer
}

\begin{abstract}
Sammendrag
Bakgrunn. Søvnsykdommer deles inn i seks hovedkategorier: insomnier, døgnrytmeforstyrrelser, søvnrelaterte bevegelsesforstyrrelser, søvnrelaterte respirasjonsforstyrrelser, hypersomnier og parasomnier. Vi ønsker her å belyse forskjeller i symptommønstre mellom disse hovedkategoriene.
\end{abstract}

Materiale og metode. Artikkelen bygger i hovedsak på diagnosemanualen utgitt av American Academy of Sleep Medicine i 2005, samt artikler funnet ved ikke-systematisk søk i PubMed.

Resultater. Lang innsovningstid er vanligst blant pasienter med insomni, forsinket søvnfase-syndrom og rastløse bein. Nattlige oppvåkninger er vanligst hos pasienter med insomni, rastløse bein og søvnapnésyndrom. Økt søvnighet på dagtid er mest uttalt hos pasienter med hypersomnier, søvnapnésyndrom og forsinket søvnfase-syndrom, mens søvnighet er sjelden et problem hos pasienter med insomni. Tretthet er vanlig ved alle søvnlidelser, spesielt ved insomni. Insomni, døgnrytmeforstyrrelser, rastløse bein og de fleste parasomnier diagnostiseres basert på anamnestiske opplysninger. Objektiv søvnregistrering er nødvendig for å stille diagnosene søvnapnésyndrom, hypersomni og periodiske beinbevegelser under søvn.

Fortolkning. Det er generelt store forskjeller i symptomatologi mellom de ulike søvnsykdommene. Ofte kan de ulike søvnsykdommene skilles fra hverandre anamnestisk uten bruk av supplerende undersøkelser, men noen pasienter bør utredes med objektiv søvnregistrering for å stille korrekt diagnose.

\section{Nicolas Øyane}

nicolas.oyane@isf.uib.no

Institutt for samfunnsmedisinske fag

Universitetet i Bergen

og

Nasjonalt kompetansesenter for søvnsykdommer Haukeland universitetssykehus

5021 Bergen

og

Bergen Søvnsenter

\section{Anne Marie van den Hoven}

Institutt for samfunnsmedisinske fag Universitetet i Bergen

\section{Arne Fetveit}

Institutt for allmenn- og samfunnsmedisin Universitetet i Oslo

\section{Ståle Pallesen}

Det psykologiske fakultet

Universitetet i Bergen

og

Nasjonalt kompetansesenter for søvnsykdommer Haukeland universitetssykehus

\section{Bjørn Bjorvatn}

Institutt for samfunnsmedisinske fag Universitetet i Bergen

og

Nasjonalt kompetansesenter for søvnsykdommer Haukeland universitetssykehus og

Bergen Søvnsenter

Søvnproblemer er svært utbredt, og $95 \%$ av alle mennesker vil i løpet av livet oppleve vanskeligheter med å sove (1). I 2005 utga American Academy of Sleep Medicine den andre utgaven av den meste detaljerte og omfattende diagnosemanualen for søvnsykdommer, International Classification of Sleep Disorders 2 (ICSD-2), som skiller mellom seks hovedkategorier søvnsykdommer (2). Ramme 1 viser en summarisk oversikt over de ulike diagnosekategoriene.

Den første gruppen, insomnier, kjennetegnes av problemer med innsovning, nattlige oppvåkninger og/eller for tidlig oppvåkning om morgenen selv om forholdene ligger til rette for søvn (2). Insomni forekommer ofte samtidig med depresjon, og søvnvansker kan generelt være et prodromalsymptom ved depresjon (3). Døgnrytmeforstyrrelser er den andre gruppen av søvnforstyrrelser (2). Ved forsinket søvnfase-syndrom har pasienten store innsovningsvansker og store problemer med å komme seg opp om morgenen (4). En sjeldnere variant, fremskyndet søvnfase-syndrom, gir et tilnærmet omvendt bilde (5). Ved den tredje diagnosegruppen, hypersomnier, er hovedsymptomene økt søvnighet på dagtid og patologisk kort innsovningstid. Den vanligste formen er selvindusert og kalles atferdsindusert, utilstrekkelig søvn-syndrom, mens narkolepsi og idiopatisk hypersomni er mer sjeldne former. Søvnrelaterte respirasjonsforstyrrelser er en fjerde gruppe søvnsykdommer, der obstruktiv søvnapnésyndrom er den hyppigste varianten. Rastløse bein og periodiske beinbevegelser under søvn tilhører en femte gruppe søvnrelaterte bevegelsesforstyrrelser. Rastløse bein beskrives som en plagsom kriblende følelse i beina, som forverres om kvelden/natten og som bedres ved bevegelse. Den siste gruppen søvnsykdommer, parasomnier, defineres som uønsket atferd eller ubehagelige fenomener som opptrer hovedsakelig eller utelukkende under søvn.

Vi ønsker i denne artikkelen å rette søkelyset på ulike symptomer hos pasienter med søvnlidelser og hvordan disse kan knyttes til ulike søvnsykdommer. Videre ønsker vi å diskutere hvor langt man kan komme differensialdiagnostisk kun ved å benytte seg av anamnestiske opplysninger.

\section{Materiale og metode}

Artikkelen er først og fremst basert på diagnosemanualen utgitt av American Academy of Sleep Medicine i 2005 (2), men er også basert på egen klinisk og forskningsbasert erfaring og på artikler funnet ved ikke-systematisk søk i PubMed.

Vi vil her diskutere de vanligste symptomene på søvnforstyrrelser og hvilke søvnsykdommer disse kan knyttes til (tab 1).

\section{Lang innsovningstid og nattlige oppvåkninger}

Problemer med innsovning er et svært vanlig symptom i befolkningen (6), uten at alle med dette problemet kan sies å ha en søvn-

\section{Hovedbudskap}

- Pasienter med ulike søvnsykdommer rapporterer svært ulike symptomer

- Insomni, døgnrytmeforstyrrelser, rastløse bein og de fleste parasomnier diagnostiseres basert på anamnestiske opplysninger

- Objektiv søvnregistrering er nødvendig for å stille diagnosene søvnapnésyndrom, hypersomni og periodiske beinbevegelser under $s ø v n$ 


\section{Ramme 1}

Hovedkategorier av søvnsykdommer
klassifisert i International
Classification of Sleep Disorders,
versjon 2 (2)
— Insomni
— Søvnrelaterte respirasjonsforstyrrel-
ser (f.eks. obstruktivt søvnapné-
syndrom)
- Hypersomni av sentralnervøs årsak
(f.eks. narkolepsi)
- Døgnrytmeforstyrrelser (f.eks. forsin-
ket søvnfase-syndrom)
- Parasomni (f.eks. søvngjengeri)
- Søvnrelaterte bevegelsesforstyrrelser
(f.eks. rastløse bein)

sykdom. Lang innsovningstid er svært ofte til stede hos pasienter med insomni (7), rastløse bein (2) og forsinket søvnfase-syndrom (8). Ved både insomni og rastløse bein vil det også ofte forekomme oppvåkninger i løpet av natten, noe som sjelden ses ved forsinket søvnfase-syndrom. Noen pasienter med obstruktivt søvnapné-syndrom vil også rapportere om nattlige oppvåkninger, men det er langt fra alltid at pasienten er klar over dette selv. Insomni ses i alle aldre, og prevalensen av kronisk insomni er om lag $10 \% \mathrm{i}$ den vestlige verden, noe som stemmer overens med funn i norske studier (9). Ved rastløse bein inkluderer diagnosekriteriene en kriblende følelse i bein eller armer som forverres om kvelden/natten og som bedres ved bevegelse (10). Sykdommen er tilsynelatende vanlig, med en prevalens på 5-15\% i Norden (11). Pasienter med forsinket søvnfase-syndrom sover vanligvis bra når de først sovner, men vil ha problemer med å komme seg opp til jobb eller skole om morgenen (8). Prevalensen av denne lidelsen er anslått å være rundt $7 \%$ hos ungdom og $0,7 \%$ hos middelaldrende $(12,13)$. Klokke- slettet de går til sengs er en viktig anamnestisk opplysning blant dem med forsinket søvnfase-syndrom, da innsovningstiden blir kortere dersom leggetiden er svært sen.

\section{Tidlig morgenoppvåkning}

Når pasienter klager over «problemer med for tidlig oppvåkning», er det sentralt å skille mellom dem som har problemer med å stå opp grunnet stor søvnighet (som ved forsinket søvnfase-syndrom), og dem som våkner spontant altfor tidlig uten å få sove igjen. I medisinsk litteratur omtales tidlig morgenoppvåkning først og fremst hos sistnevnte gruppe og er vanligst hos pasienter med insomni (7), rastløse bein (2) og fremskyndet søvnfase-syndrom (14). Ved fremskyndet søvnfase-syndrom vil pasienten normalt rapportere svært tidlig innsovningstidspunkt om kvelden, og dette syndromet anses å være meget sjeldent. Det ble blant annet ikke funnet en eneste person som oppfylte diagnosekriteriene i en undersøkelse blant over 7000 nordmenn (15).

\section{Tretthet og søvnighet på dagtid}

Både på folkemunne og til en viss grad også blant klinikere skilles det sjelden mellom trøtthet og søvnighet. Det er imidlertid diagnostisk sett viktig å kunne skille disse to symptomene fra hverandre. Økt søvnighet fører normalt til søvn/døsing på upassende tider og steder og er en naturlig konsekvens av at søvnbehovet ikke er tilfredsstilt i løpet av natten. Tretthet er derimot en subjektiv følelse av å være sliten eller utmattet. Selv om tretthet ofte kan ses i sammenheng med søvnighet, kan tretthet også ha mange andre årsaker enn umettet søvnbehov. Man kan godt være trett uten å være søvnig, som f.eks. rett etter en hard treningsøkt. Søvnighet er hyppigst rapportert av pasienter med hypersomnier, fordi søvnbehovet er patologisk økt i denne pasientgruppen (16). Den vanligste årsaken til hypersomni er atferdsindusert utilstrekkelig søvn-syndrom og skyldes at søvn nedprioriteres så mye i ukedager at personen blir sterkt søvndeprivert. På fridager kompenseres med betydelig mer søvn enn vanlig (17). Narkolepsi er en langt sjeldnere årsak til hypersomni og er rapportert å ha en prevalens på $0,3-0,5 \%$ \% $(18,19)$, mens idiopatisk hypersomni er angitt å være enda sjeldnere (20).

Søvnighet er et relativt stort problem hos pasienter med søvnapnésyndrom $(2,21)$. Den kan også være økt ved forsinket søvnfase-syndrom. At disse to pasientgruppene rapporterer økt søvnighet, har ulike årsaker. Ved forsinket søvnfase-syndrom vil innsovningstiden være lang, samtidig som pasienten ofte må stå tidlig opp for å komme seg på jobb eller skole. Når leggetid og oppvåkningstid ikke samsvarer med døgnrytmen, blir nødvendigvis søvnlengden kort (22). Dette fører til et søvnunderskudd, som igjen fører til økt søvnighet på dagtid. Grunnen til at pasienter med søvnapnésyndrom er søvnige på dagtid, er at gjentatte nattlige apnéperioder med oksygenmetningsfall og svært fragmentert søvn fører til at søvnbehovet ikke blir tilfredsstilt, til tross for at pasienten selv ofte opplever en normal eller lang søvnlengde (23). Prevalensen av søvnapnésyndrom er $2-4 \%$ i den voksne befolkningen (24). Symptomene manifesteres som snorking og pustestopp under søvn, som videre fører til hyppige nattlige oppvåkninger og økt søvnighet på dagtid (25). Obstruktiv søvnapné er vanligst hos eldre, menn og personer med overvekt/fedme. Det er også rapportert om økt risiko for kardiovaskulær sykdom og død hos personer med ubehandlet alvorlig obstruktiv søvnapné-syndrom (26). Ved en sjeldnere form, sentral søvnapné, er de sentrale respirasjonsmekanismene inhiberte. Denne formen forekommer blant annet ved alvorlig hjertesvikt og etter hjerneskade (27).

I motsetning til diagnosegruppene ovenfor er pasienter med primær insomni lite plaget med søvnighet (2). De har tvert imot problemer med å sovne på dagtid til tross for dårlig søvn om natten. Pasienter med insomni er svært ofte plaget av sterk tretthet, og studier har vist at insomnipasienter ofte rapporterer mer utmattelse/tretthet enn pasienter med andre søvnsykdommer, som søvnapné og hypersomni (21).

\section{Andre vanlige symptomer}

Pasienter med søvnvansker rapporterer ofte uttalte plager på dagtid. Både problemer med humørsvingninger og kroppslige symptomer er svært vanlig, og det kan ikke utelukkes at pasienter med søvnproblemer i enkelte tilfeller presenterer sine søvnvansker som kroppslige symptomer hos legen. For at diagnosen insomni i det hele tatt skal kunne stilles, kreves en eller annen form for nedsatt dagfunksjon, som tretthet, kognitive vansker, svekket sosial mestring, redusert yteevne i yrke eller utdanning, humørvansker, søvnighet på dagtid, redusert energi/ motivasjon, økt ulykkesrisiko, spenninger, hodepine, gastrointestinale symptomer eller bekymringer om søvnen. Det holder altså 
ikke å sove lite dersom det ikke får noen konsekvenser på dagtid.

I klinisk praksis synes ofte pasienter med insomni og samtidig depresjon å rapportere særlig mye plager på dagtid i forhold til pasienter med andre søvnsykdommer, noe som kan skyldes at deprimerte pasienter generelt har tendens til å fokusere negativt og dermed overrapportere plagsomme symptomer (28). Søvnvansker anses ofte av deprimerte pasienter som det mest plagsomme delsymptomet, og symptomer på insomni kan vedvare selv etter at pasientene er ferdigbehandlet for sin depresjon (29).

Pasienter med rastløse bein rapporterer også kroppslige symptomer. Det er naturlig, ettersom diagnosekriteriene krever at de er plaget av kriblinger i beina, spesielt på kveldstid (10). I tillegg er rastløse bein assosiert med ulike sykdommer i muskel- og skjelettsystemet (30).

\section{Symptomer knyttet til spesifikke søvnsykdommer}

Flere søvnsykdommer innenfor gruppene hypersomnier, søvnrelaterte respirasjonsforstyrrelser og parasomnier har spesifikke symptomer som kjennetegner diagnosen. En del pasienter med narkolepsi opplever også symptomer som katapleksi (plutselig tap av muskeltonus), hypnagoge og hypnapompe hallusinasjoner (hallusinasjoner under innsovning/oppvåkning) og søvnparalyse (muskelatoni under oppvåkning). Imidlertid opplever ikke alle pasienter med narkolepsi katapleksi, og ofte kan søvnigheten debutere mange år før katapleksien. Katapleksianfallene omfatter enten all skjelettmuskulatur eller kun enkelte muskelgrupper, spesielt kne- og ansiktsmuskulatur og utløses av emosjoner, hvorav latter er den vanligste (16). I tillegg er hallusinasjoner under innsovning/oppvåkning og søvnparalyse under oppvåkning ofte til stede, men disse symptomene kan også forekomme hos ellers friske mennesker eller være forbundet med andre søvnsykdommer. Ved søvnapnésyndrom vil pasientene av og til rapportere om pustestopp under søvn (31). Ved parasomnier vil ofte pårørende eller sengepartner kunne beskrive unormal atferd under søvn. Man skiller mellom parasomnier som oppstår fra dyp søvn (som søvngjengeri, nattlige skrekkanfall som er vanlige hos barn), parasomnier som oppstår fra REM-søvn (som marerittslidelse) og andre parasomnier (som søvnrelaterte spiseforstyrrelser) (2). Parasomnier, særlig dem som oppstår fra dyp søvn, og mareritt opptrer relativt hyppig, spesielt hos barn, men er sjelden så alvorlige at behandling er påkrevd.

\section{Behov for supplerende undersøkelser}

Det kan av og til være utfordrende for klinikere å skille mellom ulike søvnsykdommer, da samme symptom kan være til stede i større eller mindre grad ved flere søvnsykdommer. Vi har i denne artikkelen imidlertid vist at de ulike søvnsykdommene har såpass forskjellige symptommønstre at man ofte kan komme svært langt diagnostisk med en grundig og målrettet anamnese. Det er viktig å merke seg at vi i denne artikkelen begrenser oss til å beskrive noen sentrale primære søvnsykdommer, det vil si søvnsykdommer som ikke skyldes annen bakenforliggende sykdom eller substansbruk. Søvnproblemer kan også forekomme sekundært til en rekke medisinske tilstander og medikamentbruk, noe som alltid bør vurderes hos pasienter som klager over dårlig søvn.

Enkelte pasienter bør henvises til objektiv søvnregistrering. Multippel søvnlatenstest er sentral i diagnostisering av hypersomnier. Den innebærer 4-5 innsovningsforsøk, hver på 20 minutter, utført med to timers mellomrom utover dagen. Hypersomni dokumenteres ved en gjennomsnittlig innsovningstid på mindre enn åtte minutter (32). I tillegg vil polysomnografi normalt vise en uvanlig kort REM-latens hos pasienter med narkolepsi. Polysomnografi er også nødvendig for å påvise periodiske beinbevegelser under søvn. Denne tilstanden ses ofte hos pasienter med rastløse bein, men kan også forekomme isolert og uten at pasienten selv er klar over det. Polysomnografi viser rytmiske beinbevegelser som forstyrrer søvnen, og tilstanden forekommer hos opptil $6 \%$ av befolkningen $(33,34)$. Enkelte parasomnier kan også kreve videre utredning med polysomnografi, selv om de fleste diagnosene kan stilles anamnestisk. Objektive registreringer er også nødvendig for å utrede pasienter med mulig søvnapnésyndrom.

\section{Konklusjon}

Pasienter med ulike søvnlidelser fremviser et svært ulikt symptombilde, og en grundig anamnese er i mange tilfeller tilstrekkelig til å stille en tentativ diagnose og starte riktig behandling. På forhånd skal mulige underliggende medisinske årsaker til søvnvansker være vurdert. Diagnosekriteriene for både insomni, døgnrytmeforstyrrelser, de fleste parasomnier og rastløse bein krever ikke supplerende undersøkelser, mens både hypersomnier, søvnapné og periodiske beinbevegelser under søvn krever utredning med objektive søvnregistreringer for å fastslå en sikker diagnose. Flere søvnsykdommer kan forekomme samtidig, og enkelte diagnoser (som obstruktivt søvnapné-syndrom) kan gi alvorlige følgetilstander. Ved usikkerhet rundt diagnosen eller manglende behandlingsrespons bør også pasienten utredes med objektive søvnregistreringer.

Oppgitte interessekonflikter: Nicolas Øyane og Bjørn Bjorvatn arbeider ved det private Bergen Søvnsenter, som behandler alle typer søvnlidelser. Ståle Pallesen har også arbeidet der i løpet av de siste fem årene. Nicolas Øyane og Bjørn Bjorvath har holdt foredrag for ulike legemiddelfirmaer. De øvrige forfatterne har ingen oppgitte interessekonflikter.
Litteratur

. Ohayon MM. Epidemiology of insomnia: what we know and what we still need to learn. Sleep Med Rev 2002; 6: 97-111.

2. American Academy of Sleep Medicine. The International Classification of Sleep Disorders. 2. utg. Westchester, II: American Academy of Sleep Medicine, 2005

3. Perlis ML, Giles DE, Buysse DJ et al. Self-reported sleep disturbance as a prodromal symptom in recurrent depression. J Affect Disord 1997; 42: 209-12.

4. Weitzman ED, Czeisler CA, Coleman RM et al. Delayed sleep phase syndrome. A chronobiological disorder with sleep-onset insomnia. Arch Gen Psychiatry 1981; 38: 737-46.

5. Wagner DR. Disorders of the circadian sleep-wake cycle. Neurol Clin 1996: 14:651-70.

Balter MB, Uhlenhuth EH. New epidemiologic findings about insomnia and its treatment. J Clin Psychiatry 1992; 53 (suppl): 34-9.

7. Ohayon MM, Caulet M, Guilleminault C. How a general population perceives its sleep and how this relates to the complaint of insomnia. Sleep 1997; 20: 715-23

8. Regestein QR, Monk TH. Delayed sleep phase syndrome: a review of its clinical aspects. Am J Psychiatry 1995: 152: 602-8.

9. Pallesen S, Nordhus IH, Nielsen GH et al. Prevalence of insomnia in the adult Norwegian population. Sleep 2001; 24: 771-9.

10. Allen RP, Picchietti D, Hening WA et al. Restless legs syndrome: diagnostic criteria, special considerations, and epidemiology. A report from the restless legs syndrome diagnosis and epidemiology workshop at the National Institutes of Health. Sleep Med 2003; 4: $101-19$.

11. Bjorvatn B, Leissner L, Ulfberg J et al. Prevalence, severity and risk factors of restless legs syndrome in the general adult population in two Scandinavian countries. Sleep Med 2005: 6. 307-12.

12. Ando K, Kripke DF, Ancoli-Israel S. Estimated prevalence of delayed and advances sleep phase syndromes. Sleep Res 1995; 24: 509.

13. Pelayo R, Thorpy MJ, ovinski P. Prevalence of delayed sleep phase syndrome among adolescents Sleep Res 1988: 17.392.

14. Baker S, Zee P. Circadian disorders of the sleepwake cycle. I: Kryger MH, Roth T, Dement W, red. Principles and practice of sleep medicine. 3. utg. Philadelphia, PA: W.B. Saunders, 2000: 606-14.

15. Schrader H, Bovim G, Sand T. The prevalence of delayed and advanced sleep phase syndromes. J Sleep Res 1993; 2: 51 -5.

16. Overeem S, Mignot E, van Dijk JG et al. Narcolepsy: clinical features, new pathophysiologic insights, and future perspectives. J Clin Neurophysiol 2001; 18: 78-105.

17. Komada Y, Inoue Y, Hayashida K et al. Clinical significance and correlates of behaviorally induced insufficient sleep syndrome. Sleep Med 2008. 9: $851-6$

18. Hublin C, Kaprio J, Partinen M et al. The prevalence of narcolepsy: an epidemiological study of the Finnish Twin Cohort. Ann Neurol 1994: 35 : $709-16$.

19. Silber MH, Krahn LE, Olson EJ et al. The epidemiology of narcolepsy in Olmsted County, Minnesota: a population-based study. Sleep 2002; 25 197-202.

20. Billiard M, Dauvilliers Y. Idiopathic hypersomnia. Sleep Med Rev 2001; 5: 349-58.

21. Thorpy MJ. Which clinical conditions are responsible for impaired alertness? Sleep Med 2005; 6 (suppl 1): S13-20.

22. Czeisler CA, Weitzman E, Moore-Ede MC et al. Human sleep: its duration and organization depend on its circadian phase. Science 1980; 210 $1264-7$.

23. Goncalves MA, Paiva T, Ramos E et al. Obstructive sleep apnea syndrome, sleepiness, and quality of life. Chest 2004; 125: 2091-6.

24. Young T, Palta M, Dempsey J et al. The occurrence of sleep-disordered breathing among middle-aged adults. N Engl J Med 1993; 328: 1230-5.

25. Guilleminault C, Tilkian A, Dement WC. The sleep apnea syndromes. Annu Rev Med 1976; 27 465-84. 
26. Marin JM, Carrizo SJ, Vicente E et al. Long-term cardiovascular outcomes in men with obstructive sleep apnoea-hypopnoea with or without treatment with continuous positive airway pressure: an observational study. Lancet 2005; 365: 1046-53.

27. De Backer WA. Central sleep apnoea, pathogenesis and treatment: an overview and perspective. Eur Respir J 1995; 8: 1372-83.

28. Watson D, Pennebaker JW. Health complaints, stress and distress: Exploring the central role of negative affectivity. Psychol Rev 1989; 96: 234-54.

29. Tranter R, O'Donovan C, Chandarana P et al. Prevalence and outcome of partial remission in depression. J Psychiatry Neurosci 2002; 27: $241-7$

30. Ohayon MM, Roth T. Prevalence of restless legs syndrome and periodic limb movement disorder in the general population. J Psychosom Res 2002: 53: $547-54$

31. Kales A, Cadieux RJ, Bixler EO et al. Severe obstructive sleep apnea - I: Onset, clinical course, and characteristics. J Chronic Dis 1985; 38: 419-25.

32. Bassetti C, Aldrich MS. Narcolepsy. Neurol Clin 1996; 14: 545-71.

33. Bjorvatn B, Holsten F, Skeidsvoll H. Periodiske beinbevegelser under $s ø v n$ - kan og skal de behandles? Tidsskr Nor Lægeforen 2001; 121 2169-72.

34. Coleman RM, Pollak CP. Weitzman ED. Periodic movements in sleep (nocturnal myoclonus): relation to sleep disorders. Ann Neurol 1980; 8 :

416-21.

Manuskriptet ble mottatt 25.5. 2009 og godkjent 27.8. 2009. Medisinsk redaktør Trine B. Haugen. 